\title{
Recovering Dietary Information from Extant and Extinct Primates Using Plant Microremains
}

\author{
Amanda G. Henry
}

Received: 7 March 2011 / Accepted: 23 August 2011 /Published online: 18 November 2011

(C) The Author(s) 2011. This article is published with open access at Springerlink.com

\begin{abstract}
When reconstructing the diets of primates, researchers often rely on several well established methods, such as direct observation, studies of discarded plant parts, and analysis of macrobotanical remains in fecal matter. Most of these studies can be performed only on living primate groups, however, and the diets of extinct, subfossil, and fossil groups are known only from proxy methods. Plant microremains, tiny plant structures with distinctive morphologies, can record the exact plant foods that an individual consumed. They can be recovered from recently deceased and fossil primate samples, and can also be used to supplement traditional dietary analyses in living groups. Here I briefly introduce plant microremains, provide examples of how they have been successfully used to reconstruct the diets of humans and other species, and describe methods for their application in studies of primate dietary ecology.
\end{abstract}

Keywords Dental calculus $\cdot$ Fecal sample $\cdot$ Phytolith $\cdot$ Plant microfossil $\cdot$ Starch grain

\section{Introduction}

Understanding the dietary ecology of primate groups is a growing field (Hohmann et al. 2006), and can provide valuable information about primate behavior and evolutionary trends. The gold standard in dietary study is to follow individuals and record the foods that they consume. However, there are many populations for which this kind of analysis is not possible, including deceased primate individuals and extinct groups, and thus the diets of these groups remain largely established by proxies, such as microwear (Teaford and Walker 1984) or stable isotopes (Lee-Thorp et al. 1989). Here I describe a method new to primatology, plant microremains analysis, which is a

\footnotetext{
A. G. Henry $(\bowtie)$

Plant Foods and Hominin Dietary Ecology Research Group,

Max Planck Institute for Evolutionary Anthropology, 04103 Leipzig, Germany

e-mail: amanda_henry@eva.mpg.de
} 
powerful tool to supplement research about primate diets. Plant microremains are often diagnostic of particular plant taxa and plant organs, e.g., fruit, leaf, pith. Depending on the sampling method and questions asked, plant microremains can be used to identify the consumption of particular food sources, the variation in the consumption of food sources between seasons or among individuals, or the dietary suite of an individual or group. Importantly, plant microremains analysis provides a means to examine the diets of fossil, subfossil, recently extinct, and small isolated living populations for which we have museum collections. Plant microremains are preserved in dental calculus on teeth, and this material is easily recovered and studied from skeletal material. Plant microremains analysis can also be used to supplement traditional follow studies, and may provide additional information. For example, microremains can be isolated from fecal samples and may record the presence of foods that do not appear as macrobotanical remains. They can also be recovered from the calculus of living primates, and may provide information about plants that were consumed when the researcher was not in the field to observe that behavior. An understanding of plant microremains can therefore provide a means to explore more fully explore how living and extinct primates use their environment.

\section{An Introduction to Plant Microremains}

Plant microremains, also sometimes called plant microfossils, are microscopic remnants of plants with diagnostic morphologies that allow researchers to identify the plant taxon and occasionally plant organ that produced them. They include pollen grains, phytoliths, starch grains, and other, less diagnostic forms. Pollen grains are the male reproductive gamete of the plant. Phytoliths are small siliceous bodies formed in the leaves, husks, stems, fruits, and some underground organs (roots, corms, rhizomes, and tubers) of plants. Starch grains, or granules, are where plants store their energy, and they occur in greatest numbers and in their highest diagnostic potential in plant storage organs, such as seeds and plant underground storage organs. Starches and phytoliths are preferred for reconstructing diet because they appear in the plant organs most commonly consumed, i.e., leaves and fruits.

The word phytolith comes from the Greek words for "plant rock." Phytoliths are formed when plants concentrate soluble silica from the groundwater and deposit it in a solid, noncrystalline form within and between their cells (Pearsall 2000; Piperno 2006). Phytoliths provide structural support for plant tissues and are produced as a form of mechanical defense against herbivory because they can wear away tooth enamel (Massey and Hartley 2006; Massey et al. 2007a, b), though a contrary view is taken by Sanson et al. (2007). They are formed primarily in the above-ground organs of plants such as leaves, husks, rinds, bark, and fruits, though a few taxa accumulate them in their subterranean structures. When the plant is consumed, these siliceous bodies are not digested and are either incorporated into dental calculus or passed through the digestive system because they are resistant to most acids and very soluble only under conditions of high pH (Fraysse et al. 2009; Piperno 2006). Phytoliths have been recovered in samples dating to ca. 70 Ma (Prasad et al. 2005) and may survive much longer. 
Phytoliths take on unique morphologies depending on the plant taxon and plant part in which they formed. Commonly, the morphology is diagnostic of a relatively high taxonomic level, such as genus, tribe, subfamily, or family, but species- or cultivar-specific morphology is sometimes possible (Piperno 2006; Rapp and Mulholland 1992). Phytolith morphologies vary between and within plants by size, shape, texture, and ornamentation (Fig. 1) (Madella et al. 2005; Piperno 2006).

Starch grains are concentrations of complex carbohydrates formed in plants as a means of energy storage. There are 2 main types: transitory and reserve starch grains. Transitory starches form within the green parts of plants during the day and are transformed into sugars at night (Cortella and Pochettino 1994). They are usually small and of limited use in microremains studies (Shannon et al. 2009). Reserve starches form within various plant parts, particularly those areas where long-term energy storage is needed, such as the seeds, fruits, and underground storage organs (Sivak and Preiss 1998). These types of starches are commonly diagnostic at precise taxonomic levels such as the genus, and species-level diagnostics are sometimes possible (Piperno and Holst 1998; Piperno et al. 2000; Reichert 1913; Seidemann 1966; Torrence and Barton 2006; Torrence et al. 2004). Starch formation occurs within the amyloplasts of plant cells, and begins at a central point, called the hilum. The carbohydrate chains that make up the starch are radially deposited in alternating crystalline and amorphous shells or lamellae, which are thought to be daily growth increments (Blanshard 1987; Pérez et al. 2009). This alternating crystalline and amorphous structure gives starch grains many of their unique features, including their resiliency under certain environmental conditions, their weakness in others, and their distinctive interference cross when viewed under cross-polarized light. Starches can be preserved for long periods, at least up to $c a .200 \mathrm{kya}$, in protected environments such as dental calculus and stone tools (Henry 2010; Van Peer et al. 2003), but there are several taphonomic conditions that can damage or destroy starches, including heat, low pH, and exposure to enzymes (Biliaderis 2009; Haslam 2004; Robyt 2009). Starch grains vary in size; shape; position and appearance of the hilum, lamellae, fissures, and surface decorations; and their appearance under cross-polarized light (Fig. 2).

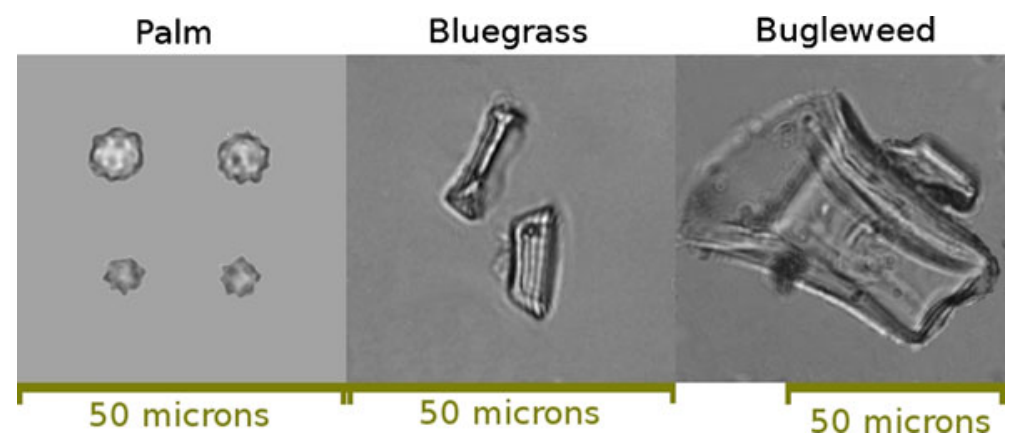

Fig. 1 Variation in phytolith morphology. Phytoliths from palm leaves (Phoenix dactylifera), a species of bluegrass (Poa bulbosa), and a species of bugleweed (Ajuga iva). Scale is indicated for each image. Note the variation in size, shape, and surface decorations. 


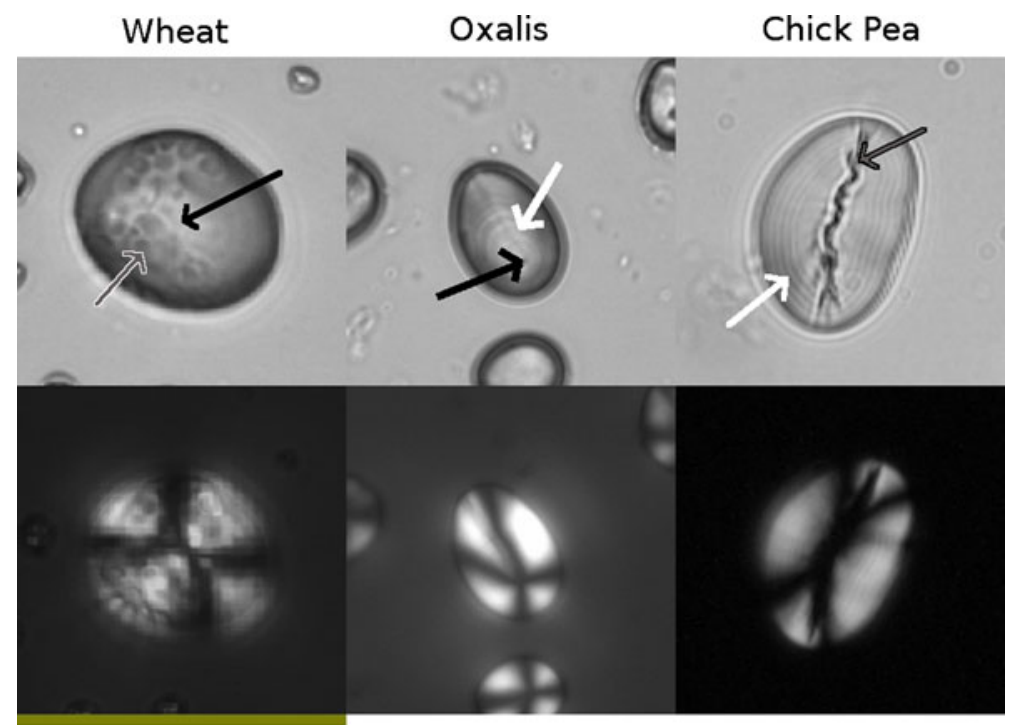

50 Microns

Fig. 2 Variation in starch granule morphology. Starch granules from wheat (Triticum aestivum), oxalis (Oxalis pes-caprae), and chick pea (Cicer arietinum) viewed under bright-field (top row) and crosspolarized (bottom row) light. Each square is $50 \mu \mathrm{m}$ on a side. Solid black arrows point to the hila, which in wheat is centric and unmarked, and in oxalis is eccentric and marked. Solid white arrows point to lamellae. The gray and white arrow points to dimples on the surface of the wheat starch. The gray and black arrow points to the large fissure on the chick pea starch.

\section{Using Plant Microremains to Recover Diet}

The durable nature and diagnostic morphologies of starch grains and phytoliths makes them an ideal tool for studying the role of plants in diet. Phytoliths and starch grains have been known to vary among plants since at least the mid-1800s when systematic microscopic studies of plants were first undertaken. In the 1970s and 1980s, researchers began to use microremains to explore the diets of human groups for which no direct data were available, focusing primarily on the use and domestication of certain plant crops (Ugent et al. 1982, 1986). Microremains are now being used to document archaeological plant use in many time periods and areas of the world (Henry et al. 2011; Li et al. 2010; Perry et al. 2007; Piperno and Becker 1996). Several researchers have shown that they can be successfully used to document diets of nonhuman species (Ciochon et al. 1990; Gobetz and Bozarth 2001; Mercader et al. 2007; Middleton and Rovner 1994). Starch grains and phytoliths can be recovered from a variety of sources, including dental calculus, fecal samples, tools, and sediment samples.

Dental calculus is the mineralized plaque that forms on the surface of teeth (Jin and Yip 2002; Lieverse 1999). Saliva is supersaturated in calcium phosphate to prevent the dissolution of the teeth during consumption of acidic foods. Oral bacteria form a skin, or pellicle, on the surface of the teeth and this roughened surface is a site for precipitation of the calcium phosphate. Layers of bacteria and calculus precipitate form, and as the calculus builds up, food particles including plant microremains become trapped in the mineral context, and are then protected from 
enzymes and other damaging materials. Recent analysis of calculus has shown that its elemental constituents are more similar to enamel than to dentine, and it is therefore a very protected environment (Henry et al. 2010). Starch grains and phytoliths preserved in calculus document the plant foods the individual consumed during life (Henry et al. 2011; Piperno and Dillehay 2008). Calculus deposits build up slowly and thus represent an average diet over an extended period of time. However, calculus formation is highly variable among individuals (Lieverse 1999), so the exact duration that the deposit represents usually cannot be determined, but is probably on the order of a few months to a few years.

Studies of primate dental calculus may be particularly useful in cases where there are few other direct means of recording diet, such as for deceased or fossil individuals. One example is the study of Gigantopithecus blacki teeth dated to 1 Mya, on which several kinds of phytoliths were recovered, including those from both grasses and fruits (Ciochon et al. 1990). A large variety and number of starch grains were recovered from the calculus of 2 modern deceased chimpanzees from the Kibale Chimpanzee Research project, showing the quantity of microremains that can be preserved in this medium (Hardy et al. 2009). Though few other studies have examined the calculus from deceased primates, the same methods have been successfully applied to a variety of human and other animal samples. Phytoliths recovered from Late Pleistocene mastodon calculus indicated that these animals consumed more grasses than previously thought (Gobetz and Bozarth 2001). Starch grains and phytoliths from historic human calculus have also provided evidence of more dietary variation than expected among these groups, including showing that Peruvian populations consumed a large number of domesticated foods much earlier than predicted (Piperno and Dillehay 2008), and that Syrian farmers consumed several kinds of wild plants in preference to the wheat and barley they grew (Henry and Piperno 2008). Calculus samples from Neanderthals also demonstrated high levels of dietary complexity, as the microremains recorded the consumption of grass seeds, dates, and plant underground storage organs (Henry et al. 2011). As these studies show, plant microremains are preserved for long periods in dental calculus, at least to 40 kya for starch grains (Henry et al. 2011), and more than 1 Mya for phytoliths (Ciochon et al. 1990).

Plant microremains can also be recovered from fecal samples and coprolites. Primate fecal samples are commonly analyzed for large macrobotanical remains (McGrew et al. 2009), but they may also contain abundant phytoliths (Reinhard and Danielson 2005). These phytoliths may record plant foods that do not leave large remains such as shells or pits, and may indicate the consumption of particular parts of these plants, e.g., leaves vs. fruits. Starch grains are less likely to survive the digestive system because they are usually hydrolyzed by digestive enzymes, but they can on occasion be recovered from fecal samples (Horrocks et al. 2004). Unlike calculus samples, coprolites and fecal samples usually represent a very short period of dietary behavior, on the order of 1 or $2 \mathrm{~d}$. Analysis of the microremains from fecal samples can provide information that may be missed by simply studying the macrobotanical remains. For example, Alouatta palliata fecal samples were analyzed for overall phytolith content to examine how seasonal dietary variation might affect dental microwear (Teaford and Glander 1996). Studies of plant microremains from fecal samples and coprolites have provided information about dietary behavior in 
other species as well. One example is the study of phytoliths from dinosaur coprolites, which showed that grasses had evolved by the Late Cretaceous and that dinosaurs regularly made use of this food resource (Prasad et al. 2005). Human coprolites also regularly preserve phytoliths, and these have been used to document everything from consumption of wild and domesticated plants by the Maori (Horrocks et al. 2002), to consumption of desert plants among the hunter-gatherers and early farmers in Texas (Reinhard and Danielson 2005).

Finally, plant microremains can also be recovered from other contexts, such as archaeological sediments and even from primate tools, which may provide information about diet. Starch grains from nuts were found on fractured rocks dated to 4.3 kya, supporting the interpretation that these rocks are the oldest evidence of dietary behavior by prehistoric chimpanzees (Mercader et al. 2007). Examining the microremains on tools from living primate food processing areas may confirm the consumption of rare foods. Sediment samples from food processing areas may also preserve phytoliths and starch grains. Taking sediment samples from several depths can provide information about change in site use through time (Parr and Carter 2003).

\section{Acquisition of Samples}

The exact research question and the availability of material will determine which samples should be collected for plant microremains analysis. Calculus samples are appropriate for questions that span longer periods of time. Acquiring calculus from museum specimens is fairly straightforward, provided that the teeth are preserved, correctly identified to species, and have not been so zealously cleaned that all the calculus has been removed. Calculus samples can also be collected from living animals. Methodologies that have been established for sedating primates and collecting close samples, e.g., blood, hair, etc., would also be appropriate for taking calculus (Glander et al. 1991). Fecal samples are best used for gathering information about short-term dietary behavior. Collecting fecal samples usually involves following a primate group and collecting samples as they fall. If the primates are well habituated or solitary it may be possible to assign the sample to a particular individual; otherwise the sample can be assigned only to the group. Coprolites may be recovered from excavations or museum collections. There is some evidence that it may be possible to determine what broad group of animals produced a coprolite (Bryant 1974), though it may be difficult to identify the exact primate species if $>1$ occupies the same area. Primate tools and sediment samples can be collected in the field from food processing areas.

\section{Methods for Isolating Microremains}

Though the details of extraction vary among sample types, the basic premise is that phytoliths and starch grains must be separated from similar-sized particles, observed under a microscope, and then identified to plant taxon or organ. Most protocols for separating microremains rely on the fact that they have different densities from the 
majority of particles that surround them, and that use of heavy liquids allows researchers to isolate them. The recovered microremains are then compared to a database of microremains recovered from modern, known plant samples, and identified based on their unique morphological attributes. What follows are some of several possible methods for processing samples. Those interested in other variations should consult Piperno (2006) and Pearsall (2000) for phytolith processing, and Torrence and Barton (2006) for starch grain processing.

Dental calculus is the easiest kind of sample to prepare. Though I and others have proposed methods that involve chemical digestion of the calculus sample (Boyadjian et al. 2007; Henry and Piperno 2008), when the calculus sample is small or easily friable, it is simplest and equally effective to remove the calculus from the tooth with a dental pick following the steps in Table I. This method has been shown to be entirely nondamaging to the enamel surface of the teeth (Henry and Piperno 2008). The sample is then mounted whole on a microscope slide in one of several kinds of mounting media. The choice of media depends on the microremain type and a full list can be found in Field (2006).

Fecal, coprolite, and sediment samples require slightly more laboratory-intensive processing. When fresh samples are collected, they should be either processed immediately or refrigerated or dried to prevent growth of bacteria or fungus that may destroy starch granules. Drying must not exceed $40^{\circ} \mathrm{C}$, as higher temperatures are known to damage starch granules (Biliaderis 2009). Once back in the laboratory, the samples are subjected to a series of processing steps, including sieving, deflocculation, and heavy liquid flotation to separate the microremains. Additional steps including the removal of organics are necessary when isolating phytoliths, but not starch grains. The exact order of these steps can vary and experimentation is recommended to establish a good methodology. I present in Tables II and III methods that work with most kinds of fecal and sediment samples.

The processing of tools can be done in a variety of ways, including picking, spot-sampling, and whole tool sonication. The raw material of the tool, e.g., wood, bone, or stone, will in part determine the method used. Sonication is best used on small, stone tools that can be taken to the laboratory. Picking, or removal of residues by a small probe, is better on tools with a complex surface morphology and distinct pits or cracks in which residues are trapped, and can be done in the field or laboratory. Spot-sampling can also be done in the field or the laboratory, and will work on a variety of tool types but will provide less

Table I Procedure for sampling dental calculus

1. Gently clean the surface of the tooth with a clean, soft toothbrush. Water can be used, depending on the condition of the tooth.

2. Hold tooth over a collection area, e.g., a piece of weighing paper or Petri dish, and gently flake or scrape off the calculus with a clean dental pick.

3. Transfer the calculus to a microcentrifuge tube if necessary for storage or transportation; otherwise place directly on microscope slide. If the sample is chunky rather than powdery, it can be gently crushed in the microcentrifuge tube with a disposable pestle.

4. If in a microcentrifuge tube, add 2-3 drops of preferred mounting medium by pipette, mix to suspend the calculus, and then use pipette to transfer the sample from the tube to the slide. 
Table II Procedure for sampling fecal or sediment samples for starch granules

1. Deflocculate: Break up any large chunks, then place $c a .5 \mathrm{ml}$ of sample in a 50 -ml centrifuge tube. Add ca. $40 \mathrm{ml}$ of a $10 \%$ solution of a deflocculant, e.g., sodium bicarbonate $\left(\mathrm{NaCO}_{3}\right)$ or sodium hexametaphosphate ((NaPO3)6), and shake vigorously, either overnight in a mechanical agitator, or by hand every $15 \mathrm{~min}$ for $6-8 \mathrm{~h}$.

2. Remove larger fraction: Pour sediment solution through a $250-\mu \mathrm{m}$ sieve into a collecting pan, using a small amount of water to rinse the sieve. Discard the larger fraction (or examine for macrobotanical remains).

3. Remove clays: Pour the contents of the collecting pan into a tall-form $600-\mathrm{ml}$ beaker $(>10 \mathrm{~cm}$ in height). Add water up to $10 \mathrm{~cm}$. Stir vigorously and allow to settle for $1 \mathrm{~h}$. Decant or aspirate half of the supernatant (which contains the clay-sized fraction). Refill to $10 \mathrm{~cm}$, stir, and allow to settle for $1 \mathrm{~h}$. Decant or aspirate $2 / 3$ of the supernatant. Repeat until the supernatant is clear after settling.

4. Transfer and rinse: Transfer sample from beaker to a 50-ml centrifuge tube. Centrifuge the tube at 2,500 $\mathrm{rpm}$ for $3 \mathrm{~min}$ and discard supernatant to make enough room in the tube to add more from the beaker. After all of the material has been transferred, centrifuge the tube and decant or aspirate all of the supernatant. Add $50 \mathrm{ml}$ of water to rinse, shake vigorously, and centrifuge and remove supernatant. Repeat the water rinse, and carefully remove as much supernatant as possible. Allow to dry slightly.

5. Float the starch granules: Add $5 \mathrm{ml}$ of cesium chloride $(\mathrm{CsCl})$ solution with a specific gravity of $1.8 \mathrm{~g} / \mathrm{ml}$. Mix carefully, and centrifuge immediately for $10 \mathrm{~min}$ at $1,000 \mathrm{rpm}$. Decant the supernatant to a fresh $50-\mathrm{ml}$ tube (the supernatant contains the starch granules and should not be discarded). Repeat this step, adding the supernatant to the same new tube. The sample remaining in the old tube can be discarded, or carefully rinsed 3 times in water and processed for phytoliths, as described below.

6. Settle and rinse: Add distilled water to fill the new 50-ml tube to reduce the specific gravity of the solution, and mix well. Centrifuge at $1,000 \mathrm{rpm}$ for $10 \mathrm{~min}$, and aspirate and discard half of the supernatant. Fill again with water, centrifuge, aspirate, and discard $c a .2 / 3$ of the supernatant. Repeat, discarding the majority of the supernatant. Rinse with water twice more, discarding the entirety of the supernatant.

7. Store or observe: The starch sample can now be immediately mounted in the preferred mounting medium, or gently dried at $\leq 40^{\circ} \mathrm{C}$ for storage.

coverage of the tool. Brushing will work on a variety of tools but may provide too much sample. Table IV describes these methods.

The imaging of microremains is done by a transmitted light microscope at $200 \times-$ $400 \times$ magnification, with cross-polarized light for analyzing starch granules. The distinguishing features of each microremain should be clearly and carefully described. For phytoliths, shape and size are the predominant features for identification, and terminology for describing phytolith shape based on geometric terms has been established (Madella et al. 2005). Starch grain features include 2- and 3 - dimentsional shape; size; position and appearance of the hilum; appearance of the lamellae; presence and appearance of internal and surface features such as cracks and dimples; and appearance under cross-polarized light. The terms used to describe these features are based on the work of Reichert (1913) and Nägeli (1858), and efforts are underway to standardize this terminology (ICSN 2011).

Analysis and identification of the sample microremains usually proceeds in 1 of 3 ways, and depends on the particular questions that the researcher is hoping to answer. First, it is possible to compare the number and variety of microremain types among samples without actually identifying the plants from which they derived. Each distinctive microremain type likely represents a single species or a few closely related taxa. Even if the actual plant species are unknown, discovering if the 
Table III Procedure for sampling fecal or sediment samples for phytoliths

1. Follow steps 1-3 in Table II, or after processing for starch granules, rinse in water, centrifuge for 5 min at 1,000 rpm, and discard the supernatant. Transfer the sample to a 14-ml glass centrifuge tube, so that there is about 1-2 $\mathrm{ml}$ of sediment in each tube, splitting the sample into several tubes if necessary.

2. Remove carbonates: (This step may not be necessary for fecal samples.) Add ca. $2 \mathrm{ml}$ of $10 \% \mathrm{HCl}$ solution, stirring carefully to prevent the reaction from spilling out of the tube. As the reaction slows, add more $\mathrm{HCl}$ until a total of $10 \mathrm{ml}$ has been added, carefully watching for a reaction. Leave the $\mathrm{HCl}$ on until any visible reaction ceases. Centrifuge for $5 \mathrm{~min}$ at 1,000 rpm, then decant the supernatant. Fill with water to rinse, stir, centrifuge for $5 \mathrm{~min}$ at $1,000 \mathrm{rpm}$, and decant. Repeat this rinse once.

3. Remove organics: Add ca. $2 \mathrm{ml}$ of concentrated nitric acid $\left(\mathrm{HNO}_{3}\right)$, stirring carefully to prevent overreaction. Slowly add more until a total of $10 \mathrm{ml}$ has been added. Place immediately in a boiling water bath, and add occasional pinches of potassium chlorate $\left(\mathrm{KClO}_{3}\right)$. Stir regularly, and apply until visible reaction ceases and the supernatant is clear yellow. This may take several hours or days. Centrifuge for $5 \mathrm{~min}$ at $1,000 \mathrm{rpm}$, and follow with 3 water rinses. This step necessarily removes any starch grains that may have been present, so this process should be carried out on separate samples or those that have already been examined for starches.

4. Optional steps: Different sediment samples may require other processing steps to isolate the phytoliths, including but not limited to treatment with hydrogen peroxide $\left(\mathrm{H}_{2} \mathrm{O}_{2}\right)$, or potassium hydroxide $(\mathrm{KOH})$. As mentioned in the text, the researcher should consult the literature regarding the specific procedures for his or her area.

5. Float the phytoliths: Add ca. $10 \mathrm{ml}$ of potassium/cadmium iodide $\left(\mathrm{KI}_{2} / \mathrm{CdI}\right)$ solution at a specific gravity of $2.3 \mathrm{~g} / \mathrm{ml}$. Mix thoroughly, then centrifuge for $5 \mathrm{~min}$ at 1,000 rpm. Using a pipette, carefully aspirate the top level of the solution, which will now contain the floating phytoliths, taking care not to jar the sample or to aspirate more than $c a .0 .5 \mathrm{ml}$. Transfer this aspirated liquid to a fresh 14-ml tube. Mix, centrifuge, and aspirate the old sample again, taking care not to aspirate more than $c a .1 \mathrm{ml}$ of liquid in total. After the second float, the new tube contains the phytoliths and the sediment sample can then be discarded.

6. Settle and rinse. Add water to fill the new tube completely, mix, and centrifuge for $10 \mathrm{~min}$ at 1,500 rpm. Aspirate and discard half of the supernatant. Add water again, mix, centrifuge, aspirate, and discard 2/3 of the supernatant. Repeat, discarding all of the supernatant. Rinse twice with water.

7. Dry: Add ca. $5 \mathrm{ml}$ acetone, mix to suspend the pellet, centrifuge for $10 \mathrm{~min}$ at 1,500 rpm, and discard the supernatant. Allow the sample to dry fully, which may take overnight.

8. Mount and observe: If the pellet is quite large, it may be necessary to separate the sample prior to mounting. If the pellet is small, add a few drops of the preferred mounting medium, mix well to suspend the phytoliths and transfer to a slide.

microremain types change, or not, can be a useful means of exploring dietary variation through time, across space, or among groups. Second, it may be possible to target certain plant species or plant organs to see if these particular food types are used by individuals or groups. Third, the general dietary suite of an individual may be of interest, and in this case, the entire collection of sample microremains is matched to plants in the reference collection. These 3 levels of analysis require different investment in a reference collection.

The value of a reference collection cannot be overstated, and its creation requires significant time and effort. First, potential foods must first be recognized and collected, usually during the season when they are used as foods, and then properly identified to taxon. The collection of primate plant foods is well described in various sources (Ortmann et al. 2006), but I recommend drying the plants at $\leq 40^{\circ} \mathrm{C}$ (rather than the $50^{\circ} \mathrm{C}$ that Ortmann et al. recommend) to avoid potential damage to starch grains. Other desiccants, such as silica gel beads, may also be useful. Once dry, the 
Table IV Procedure for sampling tools

N.B. Each of these steps can be performed individually if needed, but the entire sequence can be done if the tool is appropriate, and this provides the greatest number of microremains for analysis.

Picking: This method is appropriate for tools with pits and cracks, e.g., groundstone tools or wooden implements. Use a small probe, such as a needle, to pull out residues from the crevices on the surface of the tool. Tap the probe over a collection tube and then rinse with a stream of deionized water into the tube, or mount on a slide and view immediately.

Spot-sampling: This method is more appropriate for flaked stone tools. With a pipette, place a small drop of deionized water on a crack or flake scar. Agitate it gently with the pipette, and then transfer to a collection tube or directly to the slide for mounting.

Brushing: This method works well for larger tools. Using a small, clean brush, wash the tool in running deionized water, and collect the water. Allow the sample to settle for several hours, or centrifuge to consolidate the microremains. Remove the excess water, and mount the sample.

Sonicating: This method is best for tools that can be taken to the laboratory and are small in size. Place the tool in a glass or metal beaker and barely cover it with water. Place the beaker in a sonicator for 5$10 \mathrm{~min}$. Rinse off the tool with a stream of water, collecting the water in the same beaker. Allow the sample to settle for several hours or centrifuge to consolidate the microremains. Remove the excess water and mount the sample.

plants can be stored in plastic or paper bags, but should be monitored to prevent damage from insects or fungi. After the plants have been transferred to the laboratory, they can be examined for microremains. Isolating starch granules is quite simple: the plant organ of interest should be freshly cut to expose the inner surface, and this surface gently scraped with a scalpel over a microscope slide. A few drops of water should be added to the plant scrapings, which can then be covered with a cover glass and viewed. Harder plant parts, such as seeds, can be broken open with a mortar and pestle first, but care must be taken not to grind these samples excessively, as grinding can damage starch granules. Phytolith processing is somewhat more intensive because the organic component must first be removed. Plant fragments can be dry ashed in an oven at $500^{\circ} \mathrm{C}$, or placed in a hot oxidizing solution (as in Table II, step 3) until the organics are completely removed. Boiling the sample in nitric acid with small amounts of potassium chloride is usually sufficient to remove the organics, but additional processing with hydrogen peroxide may be necessary. The reference microremains then must be described and indexed in a manner to make matches to unknown specimens possible. Online collections such as paleobot.org can help make these reference collections easier to manage.

Though the processing of samples can seem fairly straightforward, I offer 3 notes of caution with all of these methods. First, the identification of microremains relies on considerable experience with microremain forms. Much time must be spent becoming familiar with microremain variation and building the reference collection before analyzing samples. It may be worthwhile to obtain assistance from someone with experience in this area. Second, the production of phytoliths and starch grains within plants varies significantly depending on genetic and environmental factors. Not all plants and plant organs produce microremains, so some potential foods may be invisible. Among those that do produce microremains, the presence and appearance of the starches and phytoliths may be affected by other factors, including but not limited to water availability (Madella et al. 2009), maturity of the plant 
(Czaja 1982), amount of silica in the soil (Jones and Handreck 1965), and foraging pressure on the plant (Massey et al. 2007b), and thus differences between samples may not reflect true dietary differences. Once the researcher has chosen an environment or area of study, he or she should seek out information on the production and preservation of microremains in that area. Finally, care must be taken to avoid contamination from modern microremain sources, such as other plants in the environment, dirty storage containers, and even human foods. Sampling tools, e.g., toothbrushes, dental picks, and sieves should be cleaned thoroughly between samples, preferably washing in boiling water or by using bleach or vinegar because starch granules in particular can be sticky and remain on these supplies. Another alternative for durable tools such as dental picks is to wash them thoroughly in regular water to remove phytoliths, and then flame them with a butane torch or Bunsen burner to remove starch grains (Zarrillo et al. 2008). If only a few samples are being processed, one can use new tools for each sample, e.g., fresh toothbrushes, but they should still be cleaned before use. Provided these 3 concerns are addressed, there should be few problems using microremains to examine diet.

\section{Summary}

In conclusion, plant microremains record the consumption of plants. Although no method can provide a complete picture of an organism's entire diet, microremains can provide a large window through which to examine the diets of primate groups. Microremain analysis is especially useful for documenting foods that may not otherwise be observed, particularly those eaten by extinct primate groups or deceased individuals, or foods not seen during traditional studies of living groups. Microremains can be recovered from several different sources and are thus a flexible means to answer a variety of questions about primate dietary behavior.

Acknowledgments I thank E. Vogel, J. Chalk, and P. Lucas for organizing this conference on new methods in dietary ecology; D. Piperno, L. Perry, and T. Messner for helping guide my microremains studies; and 3 anonymous reviewers for their help in improving this manuscript. This work is funded in part by a Smithsonian Institution Predoctoral Fellowship and the Max Planck Society.

Open Access This article is distributed under the terms of the Creative Commons Attribution Noncommercial License which permits any noncommercial use, distribution, and reproduction in any medium, provided the original author(s) and source are credited.

\section{References}

Biliaderis, C. G. (2009). Structural transitions and related physical properties of starch. In J. BeMiller \& R. Whistler (Eds.), Starch: Chemistry and technology (3rd ed., pp. 292-372). San Diego: Academic Press/Elsevier.

Blanshard, J. M. V. (1987). Starch granule structure and function: A physicochemical approach. In T. Galliard (Ed.), Starch: Properties and potential (pp. 16-54). New York: John Wiley \& Sons.

Boyadjian, C. H. C., Eggers, S., \& Reinhard, K. (2007). Dental wash: A problematic method for extracting microfossils from teeth. Journal of Archaeological Science, 34, 1622-1628.

Bryant, V. M. (1974). Prehistoric diet in southwest Texas: The coprolite evidence. American Antiquity, 39, $407-420$. 
Ciochon, R. L., Piperno, D., \& Thompson, R. (1990). Opal phytoliths found on the teeth of the extinct ape Gigantopithecus blacki: Implications for paleodietary studies. Proceedings of the National Academy of Sciences of the USA, 87, 8120-8124.

Cortella, A. R., \& Pochettino, M. L. (1994). Starch grain analysis as a microscopic diagnostic feature in the identification of plant material. Economic Botany, 48, 171-181.

Czaja, A. T. (1982). Kritische Untersuchungen über Bildung und Entwicklung der Triticeen-Stärkekörner (Critical examination of the development of Triticeae starch grains). Starch-Starke, 34, 109-111.

Field, J. (2006). Reference collections. In R. Torrence \& H. Barton (Eds.), Ancient starch research (pp. 95-113). Walnut Creek, CA: Left Coast Press.

Fraysse, F., Pokrovsky, O. S., Schott, J., \& Meunier, J. D. (2009). Surface chemistry and reactivity of plant phytoliths in aqueous solutions. Chemical Geology, 258, 197-206.

Glander, K. E., Fedigan, L. M., Fedigan, L., \& Chapman, C. (1991). Field methods for capture and measurement of three monkey species in Costa Rica. Folia Primatologica, 57, 70-82.

Gobetz, K. E., \& Bozarth, S. R. (2001). Implications for Late Pleistocene mastodon diet from opal phytoliths in tooth calculus. Quaternary Research, 55, 115-122.

Hardy, K., Blakeny, T., Copeland, L., Kirkham, J., Wrangham, R., \& Collins, M. (2009). Starch granules, dental calculus and new perspectives on ancient diet. Journal of Archaeological Science, 36, 248-255.

Haslam, M. (2004). The decomposition of starch grains in soils: Implications for archaeological residue analysis. Journal of Archaeological Science, 31, 1715-1734.

Henry, A. G. (2010). Plant foods and the dietary ecology of Neandertals and Modern Humans. Ph.D. thesis, The George Washington University.

Henry, A., \& Piperno, D. (2008). Using plant microfossils from dental calculus to recover human diet: A case study from Tell al-Raqā'i, Syria. Journal of Archaeological Science, 35, 1943-1950.

Henry, A. G., Brooks, A. S., Piperno, D. R., \& Rose, T. (2010). Assessing dental calculus as a source of archaeological plant microfossils using ESEM/EDS. Abstracts of the Society for American Archaeology Meetings, 2010, 116.

Henry, A. G., Brooks, A. S., \& Piperno, D. R. (2011). Microfossils in calculus demonstrate consumption of plants and cooked foods in Neanderthal diets (Shanidar III, Iraq; Spy I and II, Belgium). Proceedings of the National Academy of Sciences of the USA, 108, 486-491.

Hohmann, G., Robbins, M. M., \& Boesch, C. (Eds.). (2006). Feeding ecology in apes and other primates. Cambridge, UK: Cambridge University Press.

Horrocks, M., Jones, M. D., Beever, R. E., \& Sutton, D. G. (2002). Analysis of plant microfossils in prehistoric coprolites from Harataonga Bay, Great Barrier Island, New Zealand. Journal of the Royal Society of New Zealand, 32, 617-628.

Horrocks, M., Irwin, G., Jones, M., \& Sutton, D. (2004). Starch grains and xylem cells of sweet potato (Ipomoea batatas) and bracken (Pteridium esculentum) in archaeological deposits from northern New Zealand. Journal of Archaeological Science, 31, 251-258.

ICSN working group (2011). International code for starch nomenclature. http://fossilfarm.org/ICSN/ Code.html. Accessed 23 August 2011.

Jin, Y., \& Yip, H. (2002). Supragingival calculus: Formation and control. Critical Reviews in Oral Biology and Medicine, 13, 426-441.

Jones, J. G., \& Handreck, K. A. (1965). Studies of silica in the oat plant III. Uptake of silica from soils by the plant. Plant and Soil, 23, 79-96.

Lee-Thorp, J. A., Van Der Merwe, N. J., \& Brain, C. K. (1989). Isotopic evidence for dietary differences between two extinct baboon species from Swartkrans. Journal of Human Evolution, 18, 183189.

Li, M. Q., Yang, X. Y., Wang, H., Wang, Q., Jia, X., \& Ge, Q. S. (2010). Starch grains from dental calculus reveal ancient plant foodstuffs at Chenqimogou site, Gansu Province. Science China Earth Sciences, 53, 694-699.

Lieverse, A. R. (1999). Diet and the aetiology of dental calculus. International Journal of Osteoarchaeology, 9, 219-232.

Madella, M., Alexandre, A., \& Ball, T. (2005). International code for phytolith nomenclature 1.0. Annals of Botany, 96, 253-260.

Madella, M., Jones, M. K., Echlin, P., Powers-Jones, A., \& Moore, M. (2009). Plant water availability and analytical microscopy of phytoliths: Implications for ancient irrigation in arid zones. Quaternary International, 193, 32-40.

Massey, F. P., \& Hartley, S. E. (2006). Experimental demonstration of the antiherbivore effects of silica in grasses: Impacts on foliage digestibility and vole growth rates. Proceedings of the Royal Society B: Biological Sciences, 273, 2299-2304. 
Massey, F. P., Ennos, A. R., \& Hartley, S. E. (2007a). Grasses and the resource availability hypothesis: The importance of silica-based defences. Journal of Ecology, 95, 414-424.

Massey, F. P., Ennos, A. R., \& Hartley, S. E. (2007b). Herbivore specific induction of silica-based plant defences. Oecologia, 152, 677-683.

McGrew, W. C., Marchant, L. F., \& Phillips, C. A. (2009). Standardised protocol for primate faecal analysis. Primates, 50, 363-366.

Mercader, J., Barton, H., Gillespie, J., Harris, J., Kuhn, S. L., Tyler, R., \& Boesch, C. (2007). 4,300-Yearold chimpanzee sites and the origins of percussive stone technology. Proceedings of the National Academy of Sciences of the USA, 104, 3043-3048.

Middleton, W. D., \& Rovner, I. (1994). Extraction of opal phytoliths from herbivore dental calculus. Journal of Archaeological Science, 21, 469-473.

Nägeli, C. (1858). Die Stärkekörner: Morphologishe, physiologishe, chemisch-physicalisch und systematisch-botansiche. Zurich: Verlag F. Schulthess.

Ortmann, S., Bradley, B. J., Stolter, C., \& Ganzhorn, J. U. (2006). Estimating the quality and composition of wild animal diets - a critical survey of methods. In G. Hohmann, M. Robbins, \& C. Boesch (Eds.), Feeding ecology in apes and other primates (pp. 397-422). Cambridge, UK: Cambridge University Press.

Parr, J. F., \& Carter, M. (2003). Phytolith and starch analysis of sediment samples from two archaeological sites on Dauar Island, Torres Strait, northeastern Australia. Vegetation History and Archaeobotany, 12, 131-141.

Pearsall, D. M. (2000). Paleoethnobotany: A handbook of procedures. San Diego: Academic.

Pérez, S., Baldwin, P. M., \& Gallant, D. J. (2009). Structural features of starch granules I. In J. BeMiller \& R. Whistler (Eds.), Starch: Chemistry and technology (3rd ed., pp. 149-192). San Diego: Academic Press/Elsevier.

Perry, L., Dickau, R., Zarrillo, S., Holst, I., Pearsall, D. M., Piperno, D. R., Berman, M. J., Cooke, R. G., Rademaker, K., Ranere, A. J., Raymond, J. S., Sandweiss, D. H., Scaramelli, F., Tarble, K., \& Zeidler, J. A. (2007). Starch fossils and the domestication and dispersal of chili peppers (Capsicum spp. L.) in the Americas. Science, 315, 986-988.

Piperno, D. R. (2006). Phytoliths: A comprehensive guide for archaeologists and paleoecologists. Lanham, MD: AltaMira Press.

Piperno, D. R., \& Becker, P. (1996). Vegetational history of a site in the central Amazon basin derived from phytolith and charcoal records from natural soils. Quaternary Research, 45, 202-209.

Piperno, D. R., \& Dillehay, T. D. (2008). Starch grains on human teeth reveal early broad crop diet in Northern Peru. Proceedings of the National Academy of Sciences of the USA, 105, 1962219627.

Piperno, D. R., \& Holst, I. (1998). The presence of starch grains on prehistoric stone tools from the humid Neotropics: Indications of early tuber use and agriculture in Panama. Journal of Archaeological Science, 25, 765-776.

Piperno, D. R., Ranere, A. J., Holst, I., \& Hansell, P. (2000). Starch grains reveal early root crop horticulture in the Panamanian tropical forest. Nature, 407, 894-897.

Prasad, V., Strömberg, C. A. E., Alimohammadian, H., \& Sahni, A. (2005). Dinosaur coprolites and the early evolution of grasses and grazers. Science, 310, 1177-1180.

Rapp, G. J., \& Mulholland, S. C. (1992). Phytolith systematics: Emerging issues. New York: Plenum Press.

Reichert, E. T. (1913). The differentiation and specificity of starches in relation to genera, species, etc. Washington, DC: The Carnegie Institution.

Reinhard, K. J., \& Danielson, D. R. (2005). Pervasiveness of phytoliths in prehistoric southwestern diet and implications for regional and temporal trends for dental microwear. Journal of Archaeological Science, 32, 981-988.

Robyt, J. F. (2009). Enzymes and their action on starch. In J. BeMiller \& R. Whistler (Eds.), Starch: Chemistry and technology (3rd ed., pp. 237-292). San Diego: Academic Press/Elsevier.

Sanson, G. D., Kerr, S. A., \& Gross, K. A. (2007). Do silica phytoliths really wear mammalian teeth? Journal of Archaeological Science, 34, 526-531.

Seidemann, J. (1966). Stärke-Atlas. Berlin: Paul Parey.

Shannon, J. C., Garwood, D. L., \& Boyer, C. D. (2009). Genetics and physiology of starch development. In J. BeMiller \& R. Whistler (Eds.), Starch: Chemistry and technology (3rd ed., pp. 23-82). San Diego: Academic Press/Elsevier.

Sivak, M. M., \& Preiss, J. (Eds.). (1998). Starch: Basic science to biotechnology. San Diego: Academic. Teaford, M. F., \& Glander, K. E. (1996). Dental microwear and diet in a wild population of mantled howling monkeys (Alouatta palliata). In M. A. Norconk, A. L. Rosenberger, \& P. A. Garber (Eds.), Adaptive radiation of Neotropical primates (pp. 433-450). New York: Plenum Press. 
Teaford, M. F., \& Walker, A. (1984). Quantitative differences in dental microwear between primate species with different diets and a comment on the presumed diet of Sivapithecus. American Journal of Physical Anthropology, 64, 191-200.

Torrence, R., \& Barton, H. (Eds.). (2006). Ancient starch research. Walnut Creek, CA: Left Coast Press.

Torrence, R., Wright, R., \& Conway, R. (2004). Identification of starch granules using image analysis and multivariate techniques. Journal of Archaeological Science, 31, 519-532.

Ugent, D., Pozorski, S., \& Pozorski, T. (1982). Archaeological potato tuber remains from the Casma Valley of Peru. Economic Botany, 36, 182-192.

Ugent, D., Pozorski, S., \& Pozorski, T. (1986). Archaeological manioc (Manihot) from Coastal Peru. Economic Botany, 40, 78-102.

Van Peer, P., Fullagar, R., Stokes, S., Bailey, R. M., Moeyersons, J., Steenhoudt, F., Geerts, A., Banderbeken, T., De Dapper, M., \& Geus, F. (2003). The early to middle stone age transition and the emergence of modern human behaviour at site 8-B-11, Sai Island, Sudan. Journal of Human Evolution, 45, 187-193.

Zarrillo, S., Pearsall, D. M., Raymond, J. S., Tisdale, M. A., \& Quon, D. (2008). Directly dated starch residues document early formative maize (Zea mays L.) in tropical Ecuador. Supplementary material. Proceedings of the National Academy of Sciences of the USA, 105, 5006-5011. 